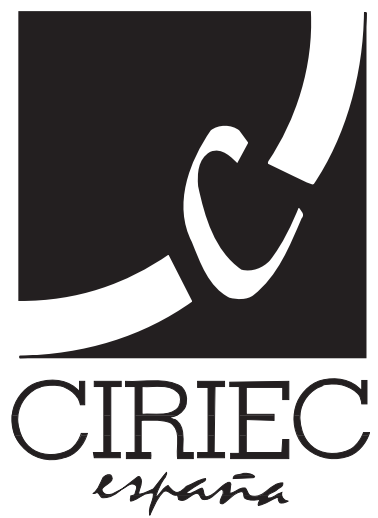

CIRIEC-España, Revista de Economía Pública, Social y Cooperativa, nº 88, Diciembre 2016, pp. 201-230

\title{
De la innovación social a la economía solidaria. Claves prácticas para el desarrollo de políticas públicas
}

\author{
Santiago Eizaguirre Anglada \\ Universitat de Barcelona
}

Cómo citar este artículo / How to cite this article: EIZAGUIRRE, S. (2016): "De la innovación social a la economía solidaria. Claves prácticas para el desarrollo de políticas públicas", CIRIEC-España, Revista de Economía Pública, Social y Cooperativa, 88, 201-230.

CIRIEC-España, revista de economía pública, social y cooperativa ISSN edición impresa: 0213-8093. ISSN edición online: 1989-6816.

(C) 2016 CIRIEC-España 


\title{
De la innovación social a la economía solidaria. Claves prácticas para el desarrollo de políticas públicas
}

\author{
Santiago Eizaguirre Anglada
}

\section{RESUMEN}

El presente artículo ahonda en la identificación de puntos en común entre la multitud de prácticas que constituyen lo que se conoce como economía social y solidaria (ESS) y el fomento de la innovación social como un reto actual para las políticas públicas. El objetivo es evaluar los modos en que las Administraciones pueden hacer hincapié en favor de la economía social y solidaria considerando su importancia estratégica para el desarrollo económico local. El texto combina la revisión de la literatura específica con la exposición de experiencias ubicadas en la provincia de Barcelona partiendo de un trabajo de campo desarrollado mediante entrevistas en profundidad con informadores privilegiados entre los años 2009 y 2012. Se analizan los mecanismos divulgativos, las medidas públicas y los estímulos administrativos más comunes entre gobiernos locales y regionales para el fomento de la ESS. Finalmente se concluye que el fomento de la innovación social requiere un enfoque integral que supere la división de las políticas públicas en compartimientos estanques, y que este enfoque, a pesar de que existen dificultades evidentes para que sea escalado en un marco de gobernanza multinivel, ofrece una ventana de oportunidad para la popularización de las prácticas que tienen como objetivo la democratización de la economía.

PALABRAS CLAVE: Innovación social, economía social y solidaria, desarrollo económico local, coproducción de políticas públicas, gobernanza democrática.

CLAVES ECONLIT: 035, B50, 031.

Cómo citar este artículo / How to cite this article: EIZAGUIRRE, S. (2016): "De la innovación social a la economía solidaria. Claves prácticas para el desarrollo de políticas públicas", CIRIEC-España, Revista de Economía Pública, Social y Cooperativa, 88, 201-230.

Correspondencia: Santiago Eizaguirre Anglada, Universitat de Barcelona, Departament de Sociologia. GRC Creativitat, Innovació i Transformació Urbana, e-mail: santieizaguirre@ub.edu. 


\section{EXPANDED ABSTRACT}

\section{From social innovation to the solidarity-based economy: key practices for the development of public policies}

Identifying the existence of democratic governance rules in economic activities is considered a necessary first step towards linking the solidarity-based economic sector to the promotion of social innovation. Faced with a non-critical use of the notion of social innovation (and considering that democratic economic principles applied to business activities always manifest themselves gradually), one of the first issues to be tackled in order to foster social innovation with socially transformative aims is to identify certain basic principles to define economic practices that may be included within what is known as the social and solidarity-based economy. As the previous literature has shown, these practices are basically defined by their aims and by their governance rules and they are not directly linked to an exclusive legal form. Although the sector has been historically and ideologically related to the development of democratic cooperativism, the practices that can be framed within the social and solidarity-based economy are defined primarily by the ways in which they face the effects of different economic cycles in terms of social and ecological transformation. In addition to the search for a human and socially transformative scale for economic activity, one of the main common criteria signalled in the literature is the identification of participative and democratic governance practices in business decision-making. This involves the development of strategies to consider the complexity occasioned by the existence of a growing multiplicity of types of actors engaged in economic processes, in consonance with what are called multi-stakeholder dynamics. In this sense, economic activity may be an area of democratic experimentation and the search for private gain is no longer going to be the main ruling principle of the system.

The positive disposition towards social innovation shown by initiatives framed within the social and solidarity-based economy is reinforced by their inclination to link non-speculative productive activities with democratic development, but also by many of their organisational aspects. The resilience of the sector's entities, or the economic risk that they are capable of assuming, has popularised (especially in the current context of multidimensional crisis) the identification of the sector with an approach that confronts the multiple social challenges that emerge in the context of economic globalisation and its particular negative effects on territories. These types of economic practices are especially suited both to fostering partnerships between different kinds of actors involved in the provision of welfare services and to promoting an integrated approach to local economic development. Since the mid-1990s, there has been an awareness in Europe of the third sector's role in providing solutions to basic social ser- 
vices, considering the growing importance of new modes of organisation as well as new productive factors. This is linked to the increase of different types of actors with different forms of commitment and different modes of operation that define social enterprises as especially hybrid organisations in comparison to hegemonic forms of private enterprise. From the public administration's perspective, this coincides with the social innovation paradigm in which public management systems may gain in complexity by adapting themselves to issues such as the activation of citizens as co-producing agents of public services. Other innovative trends with a special presence in the social and solidarity-based sector are: the intensive use of the Internet; the adoption of crowdsourcing dynamics; the cooperative consumption of goods and services; the initiatives' territorial sense of belonging; the emphasis on the construction of communities supporting concrete collective practices; or multi-activity as a principle promoting entrepreneurialism, among others. In addition to these organisational dynamics, it is necessary to consider changes in production factors. For instance, the social sector has witnessed and adapted itself to growing selectivity in volunteer work and organisational activism, which nowadays are especially geared towards concrete aims. Also, it has been particularly exposed to the effects of the influx of financial resources from public policies in terms of the aims, objectives, and working dynamics that drive the operation of social entities.

Considering the previously cited aspects, and approaching the main question of the research from a local administration perspective, it is crucial to consider the importance and complexity of promoting and spreading knowledge of a set of economic practices that are not easily parameterised. Through an analysis of the existing literature and the consideration of different case studies derived from our fieldwork in the province of Barcelona, we can underline three basic mechanisms used by municipalities in this regard: (1) the organisation of citizen awareness-raising events; (2) the study and parameterisation of the sector; and (3) the development of outreach activities geared towards policy makers and public managers. The strategy of awareness-raising through the organisation of events requires avoiding the 'folklorisation' of the sector and the linking of its popularisation to situations of exceptionality. In turn, the study and parameterisation of the sector involves confronting analytical complexity in its delimitation and developing a shared diagnosis in conjunction with the sector itself. Lastly, with regard to popularisation among policy makers and public managers, it is crucial to avoid the risk of sectorialisation that policies geared towards the promotion of the solidarity-based economy have. This means seeking a cross-cutting approach in the incorporation of economic democratisation principles.

On the other hand, apart from the popularisation of the sector, there is a set of administrative stimuli and concrete executive measures used by some municipalities to promote the sector. Financial supports for social entrepreneurs, aimed at helping small initiatives in their development phase, are useful mechanisms, especially in the search for providers responding to local needs. Another promotional measure is to support those spaces that are useful for backing socio-communitarian activities, fostering collective learning about the challenges for local development and exploring the intersection between entrepreneurial activities and citizenship practices. In this regard, local governments can also foster exchanges between networks, as well as boost complementary currencies as a tool to tackle 
financial scarcity and to promote labour activation, while at the same time offering opportunities to small businesses. In this sense, we can also identify the introduction of social clauses in the administration's contracts as a way to incorporate social and environmental criteria in contract documents and as a policy tool allowing multiple applications. Lastly, public stimulus for business transformation involves encouraging the improvement of social, economic, and ecological aspects through incentives for the private sector.

Despite the variety of possibilities presented here for public policies linking social innovation and solidarity-based economic practices, and in an effort to offer some practical conclusions, it is important to point out several limitations. Firstly, public policies fostering the sector have to face the crucial difficulty of the absence (for the meantime) of a clear articulation of the interests of the social and solidarity-based sector at the macroeconomic level. This is considered a necessary step to guarantee the positive development of the relative weight of the social and solidarity-based sector in relation to the rest of economic activity. Secondly, it is necessary, as already indicated, to seek cross-cutting and integrated approaches in policies fostering social and solidarity-based economic practices. This means avoiding their institutionalisation as a specific activity niche within public policies and promoting their presence as a driving principle in all public management areas. Lastly, a third important unresolved issue for public policies fostering social innovation is that the social and solidarity-based economy, in its operating and governance principles, is geared towards the subversion of the hegemonic model of the capitalist enterprise motivated by private profit. As a consequence, this requires a complementary effort not only in favour of the emergent sector but also in favour of defending economic democracy in a broad sense. This means, for instance, penalising and regulating the scope of business practices that are contrary to the principles of social and environmental justice.

KEYWORDS: Social innovation, social and solidarity-based economy, local economic development, co-production of public policies, democratic governance. 


\section{1.- Introducción}

"La innovación social no puede ser reducida a la economía social y solidaria, pues cubre un abanico más amplio de motivaciones individuales, así como de acción colectiva, redes sociales, formas organizacionales y en definitiva transformaciones sociales que no pueden ser reducidas en un sentido económico". Así se expresa Laurent Fraisse (2013: 361) para responder a la cuestión sobre la vinculación entre las nociones de innovación social y economía social y solidaria. La innovación social es un concepto contenedor que engloba muchos más ámbitos de la experiencia humana organizacional y colectiva que el económico. Una cuestión que paradójicamente también se puede afirmar pensando en la economía social y solidaria, sus múltiples encarnaciones y manifestaciones culturales. La economía solidaria, como la innovación social, tampoco puede ser reducida en prácticas o formas organizativas en un sentido estrictamente económico.

Otra cuestión previa clave en la vinculación entre ambos marcos teóricos es que no todas las iniciativas e organizaciones vinculadas a la economía social y solidaria tienen porqué considerarse como innovadoras. Esta misma observación también aparece en algunos de los debates académicos publicados entorno la definición de experiencias de innovación social. Es común afirmar que la innovación social entendida como el desarrollo de soluciones mercantiles a necesidades sociales que no eran atendidas previamente ni por agentes privados ni por el Estado simplemente son en muchos casos nuevas combinaciones de factores productivos y agentes de producción previamente existentes.

Es en estos puntos de encuentro entre ambas perspectivas que podemos considerar que es interesante el estudio sobre cómo las Administraciones públicas, con su énfasis renovado en la noción de innovación social, pueden incidir en promocionar las prácticas de la economía social y solidaria. El riesgo de la reproducción de isomorfismos institucionales a través de la presión del mercado, o también de la presión impuesta por las Administraciones públicas, es una de las cuestiones que más ha preocupado a los estudiosos del tercer sector social, la economía cooperativa o la economía social y solidaria. Esta es una cuestión que también preocupa a todas esas personas que se interesan por las implicaciones políticas de la existencia de estrategias de producción, distribución y consumo que no responden necesariamente a los códigos hegemónicos en un mercado capitalista.

La noción de innovación social despierta especial suspicacia especialmente entre académicos críticos y actores pertenecientes a los movimientos sociales de inspiración anticapitalista. Principalmente despierta sospechas entre personas comprometidas con la transformación social y la lucha por el cambio en las relaciones de poder. Se entiende que, la innovación -un concepto genuinamente asociado al capitalismo (Gurrutxaga, 2011; Gurrutxaga y Uncueta, 2006)-, cuando se adjetiva con el término social, lo que se busca es hacer referencia a un capitalismo de cara amable que se preocupa por la 
cohesión social (Novy et al., 2012) y en el que en la mayoría de los casos la expresión innovación social sirve como eufemismo de la externalización a la sociedad civil de las responsabilidades públicas vinculadas a los derechos de ciudadanía (Eizaguirre et al., 2012; Pradel et al., 2013; Martinelli, 2013). Partiendo de la aceptación de esta sospecha crítica, este artículo ahonda en la idea que el énfasis en la noción de innovación social puede ser utilizado para el desarrollo de políticas públicas en favor de esas prácticas económicas, normalmente identificadas con la economía social y solidaria, que se plantean incidir en la transformación social y política de las relaciones de poder generadoras de desigualdad y exclusión.

Partimos de la existencia de un interés evidente en la promoción de la innovación social como un mecanismo discursivo estratégico usado en las políticas públicas en general para hacer frente a un contexto en que entre otras cosas las Administraciones públicas han sido despojadas de recursos. No obstante, a parte de la escasez de recursos, la necesidad de coproducción de políticas públicas entre las Administraciones y la ciudadanía está motivada por un contexto de cambio de época (Subirats, 2014), en que los roles tanto de la ciudadanía como de las Administraciones están cambiando y en el que las redes entre ellos son cada vez más determinantes para hacer frente a los retos socioeconómicos contemporáneos. Unos retos que tienen una naturaleza multidimensional o poliédrica en la que se hace difícil separar los aspectos políticos, de los culturales y los ecológicos, entre otros.

A pesar de que no es toda la producción literaria al respecto de la noción de innovación social, es mucha la literatura que identifica la innovación social con las prácticas vinculadas a la economía social y solidaria (Conill 2014; Estivill 2014; Gerometta, Häussermann y Longo 2005; Jiménez y Morales, 2011; Laville 2010; Moulaert y Nussbaumer, 2005; Moulaert 2009; Paniagua Zurera 2013). Laurent Fraisse (2013) da tres razones para explicar esta vinculación. En primer lugar señala que una de las explicaciones posibles es que los objetivos sociales de la actividad económica son muy presentes en las empresas e iniciativas de la economía cooperativa, social y solidaria. En segundo lugar destaca que las prácticas de la economía social y solidaria han sido muy activas en la innovación de las formas de actividad empresarial dando pie a la aparición de empresas con un estatuto no capitalista basadas en prácticas de autogestión. En esta misma dirección la economía social y solidaria está contribuyendo activamente a la comprensión del papel crucial que juegan las prácticas económicas de carácter no capitalista en el objetivo de conseguir el bienestar social, el desarrollo económico y la regeneración ambiental (Fraisse 2013).

Tomando perspectiva sobre las políticas locales en favor de la economía social y solidaria en Francia, Fraisse destaca que a partir de la década de los 80 se da una primera fase de institucionalización de la economía social a nivel nacional, pero que no es hasta la primera década del siglo XXI que se dan los primeros signos de integración de la economía social y solidaria en la acción pública. Ciudades como Nantes, Grenoble o Lille, y regiones como Nord-Pas de Calais; Provence-Alpes-Cote d'Azur han adoptado medidas que vinculan el fomento de iniciativas ligadas a la economía social y solidaria con el desarrollo sostenible, la activación laboral y la cooperación descentralizada en las políticas regionales de promoción económica. En el contexto del Estado español en 2015, en parte a raíz 
de la llegada de las denominadas "candidaturas del cambio" al poder en distintos ayuntamientos de ciudades importantes, la economía social y solidaria ha adquirido un impulso significativo en la agenda política a nivel municipal.

En este debate sobre innovación social y políticas públicas hay una pregunta clave que es en qué sentido la economía social y solidaria puede considerarse como un nuevo campo para la acción de las políticas públicas (Moulaert et al. 2013; VV.AA 2014; Coraggio, 2013; Dacheux \& Goujon, 2011; Nunes, 2007; Singer, 2009). Laurent Fraisse (2013) entre muchos otros, ha abordado la cuestión revisando experiencias en el marco de los gobiernos municipales y regionales del Estado francés. Para Fraisse el énfasis en la innovación social es un campo estratégico para la construcción de unas políticas públicas que impulsen y den relieve a las iniciativas de economía social y solidaria. De modo paralelo a los discursos sobre innovación social se impone en el sino de las Administraciones públicas, tanto para gestores como sus representantes políticos, una visión cada vez mayor respecto la necesidad de relacionar las distintas áreas de las políticas públicas que han funcionado históricamente como compartimentos estanco. La vinculación entre desarrollo económico, consumo de proximidad y responsabilidad social corporativa, es cada vez más evidente, por ejemplo. Esto incide positivamente en la visualización de las iniciativas que buscan la democratización de la economía porque se caracterizan por considerar la complejidad y la interconexión entre la dimensión social, cultural y política de la actividad económica.

\section{2.- Nota metodológica}

El objetivo principal del texto es ofrecer una revisión general de la literatura sobre fomento de la economía solidaria por parte de las Administraciones locales. El análisis bibliográfico se complementa con apuntes sobre iniciativas económicas y prácticas de políticas públicas que fomentan la economía solidaria principalmente a nivel local en el contexto geográfico de la provincia de Barcelona.

Las observaciones y el material empírico expuesto se derivan del trabajo de campo desarrollado entre 2009 y 2012 en el marco de una investigación doctoral en la que el estudio del fomento de la economía solidaria en Barcelona tuvo un lugar preponderante (Eizaguirre, 2012). Los hallazgos de esta investigación se han complementado con el seguimiento de políticas públicas a nivel local entre 2012 y 2016. La selección de ejemplos de políticas públicas y casos de prácticas de economía solidaria que se presentan en este texto se sustenta en el seguimiento de experiencias de innovación social principalmente mediante el análisis de veintiséis entrevistas en profundidad con informadores privilegiados. La recogida de evidencias ha sido complementada en base al análisis de fuentes de datos secundarios y documentación generada por el sector. La composición de la muestra de infor- 
madores privilegiados entrevistados se realizó buscando la complementariedad entre tres tipos diferentes de informadores. Se entrevistó a catorce informadores referentes al funcionamiento interno de prácticas de ciudadanía vinculadas al fomento de la economía solidaria, con los que se inquirió al respecto de la historia de las iniciativas, sus relaciones de gobernanza con la administración, y las formas de evaluar su impacto en las políticas públicas. También se realizaron ocho entrevistas con informadores representantes de Administraciones públicas con contacto con el sector, profundizando en los cambios en la gobernanza promovidos por prácticas de economía solidaria así como sobre el desarrollo de políticas públicas relacionado con el sector. Finalmente se complementó la recogida de datos mediante entrevistas con cuatro académicos conocedores de los ámbitos de innovación pública en los que el sector está involucrado. Los criterios de selección de los ejemplos presentados en este artículo responden a la voluntad de ilustrar las principales tendencias emergentes entre prácticas de economía solidaria, así como a la ejemplificación de los principales mecanismos de divulgación y de fomento de la actividad, por parte de las Administraciones públicas.

Por último, por lo que respecta a las estimaciones cuantitativas del sector se hace referencia a fuentes secundarias de datos derivadas de los estudios promovidos por la Diputación de Barcelona (Garcia Jané, 2014), y el Ayuntamiento de Barcelona (Fernández y Miró, 2016), así como al directorio de prácticas de la Xarxa d'Economia Solidària de Catalunya.

\section{3.- Identificar las reglas de gobernanza democrática de las actividades económicas}

Para encapsular la dimensión social de las empresas pertenecientes al sector solidario Jaques Defourny y Marthe Nyssens (2013) hablan de tres indicadores básicos: el hecho de que las entidades en cuestión tengan el objetivo explícito de beneficiar a la comunidad; que se trate de iniciativas promovidas por un grupo de ciudadanos o organizaciones; y que tengan una posición clara por lo que respecta a la limitación de la distribución de beneficios. Esta última dimensión sobre la limitación de la distribución de beneficios caracterizaría a una iniciativa económica en tanto que solidaria, pues plantea la cuestión ética que cualquier forma de enriquecimiento sin límites implica necesariamente procesos de desposesión para otros actores.

Ante la discusión sobre formas jurídicas alrededor de lo que es y no es el tercer sector, la perspectiva de la economía social y solidaria pone el énfasis entre otras cuestiones en las normas de gobernanza de las actividades económicas. Más allá de la observación del objetivo de producir bienes, recursos y/o servicios con un aporte social, la aproximación legal e institucional que proponen los estudios sobre la economía social y solidaria tiene que ver con la promoción y la divulgación de una ética democrática de las relaciones económicas (Herrán, 2013; J. Garcia, 2012, 2014; Oliveres, 2006). Esto 
implica entender la economía social y solidaria como un conglomerado de actividades que puede incluir cooperativas, asociaciones, sociedades mutuales, fundaciones sin ánimo de lucro, la mayoría de ellas organizaciones que no pertenecen exclusivamente a sus socios, entre otros esquemas legales que conforman lo que se conoce como la economía social. El sector se caracteriza por aglutinar distintos tipos de organizaciones que tienen en común unas reglas específicas de gobernanza interna y externa. Por un lado las prácticas del sector están comprometidas con el desarrollo de la democracia en la gestión y toma de decisiones económicas. Por otro lado el sector se caracteriza por encarnar esas prácticas económicas que se rigen por la búsqueda de resultados democratizadores en las relaciones sociales que generan. Es ejemplar de la superación del enfoque jurídico-organizacional en la definición del sector el hecho que la Xarxa d'Economia Solidària de Catalunya', -que es la red que aglutina las entidades, colectivos y personas que se identifican con el sector en Catalunya-, permita su filiación a personas físicas a modo individual, reconociendo el hecho que las prácticas económicas de tipo productivo orientadas a la transformación social y a la democratización de las relaciones económicas pueden también incluir la actividad desarrollada por sociedades laborales o profesionales autónomos a título individual.

En este punto es importante señalar que las reglas de gobernanza de las iniciativas de la economía social y solidaria tienen que ver con valores que se pueden relacionar históricamente con el cooperativismo democrático. Eso incluye en primer lugar la gestión independiente de las empresas, el desarrollo de procesos de toma de decisiones democráticas y la primacía de las personas y el trabajo por delante del capital en la distribución de los beneficios de la actividad. 0 sea aquello específico del sector social y solidario tiene que ver de modo muy primordial con las normas y criterios que rigen la toma de decisiones empresariales. Una gobernanza basada en una cultura genuinamente democrática implicaría por ejemplo que la toma de decisiones no depende de la propiedad del capital social de la entidad sino que se rige por criterios igualitarios y en los que las personas que participan de los órganos rectores están ahí por su implicación en los procesos desarrollados por las organizaciones, ya sea como productores, como usuarios, como beneficiarios, o como simpatizantes o promotores. El caso de la cooperativa de servicios financieros COOP $57^{2}$ y su organización asamblearia descentralizada en secciones territoriales en la que los votos de los socios se ponderan de modo independiente del capital aportado, es un ejemplo de la aplicación de este requisito de evitar la preponderancia del capital frente a las personas en la toma de decisiones.

Relacionado con la participación en la toma de decisiones otro criterio común entre autores que se acercan a la cuestión sobre la gobernanza democrática en las empresas sociales es la naturaleza participativa de las iniciativas que se plantean la incorporación en la construcción de consensos de todos los tipos de personas que participan de ellas ya sea como actores, personas usuarias beneficiarias o como personas afectadas por la actividad de la entidad. Esta característica aparece como un

1.- Disponible en http://www.xes.cat/ acceso el: 25/07/2016.

2.- Disponible en http://coop57.coop/ acceso el: 25/07/2016. 
reto a tener en cuenta en un futuro inmediato cuando consideramos la innovación social desde la perspectiva de las Administraciones públicas (Lévesque, 2013). Cuando hablamos de la importancia de la coproducción de políticas públicas teniendo en cuenta la perspectiva de los usuarios de estas, estamos haciendo referencia a este aspecto en concreto que podría representar una de las características intrínsecas de las iniciativas y experiencias que pueden identificarse como innovación social. La coproducción de la toma de decisiones, ya sea referida a políticas públicas o a la gobernanza de iniciativas empresariales, conduce a la consideración de los equilibrios entre distintos tipos de actores. Una de las características identificadoras de los procesos de innovación social, también muy presente en las empresas de la economía solidaria, es la interacción productiva entre distintos tipos de actores: las dinámicas multi-stakeholder. La consideración de la existencia de distintos tipos de actores que intervienen en la toma de decisiones también es un reto en el estudio de los mecanismos de participación democrática en el siglo XXI (Parés, 2015).

Jordi García Jané (2014) se refiere a la definición de la economía social y solidaria como esas prácticas que dan primacía a la satisfacción de necesidades humanas por encima del lucro, gestionan su actividad de modo democrático y están comprometidas con su medio natural y social con la perspectiva de la transformación social. Es precisamente esta orientación a la transformación social lo que incide en que como economía social y solidaria nos referimos a prácticas, más allá de empresas y entidades, subrayando que la forma jurídica que adopten los actores para regular su actividad es secundaria. Relacionada con la tendencia a identificar la economía social y solidaria con un tipo de forma jurídica (las cooperativas), una de las críticas del sector hacia la regulación normativa mediante leyes de cooperativas es que tienden a "empresarializar" el sector (J. Garcia, 2014). Si entendemos la economía social y solidaria como prácticas económicas que promueven procesos por la transformación social nos encontramos con la necesidad de incluir distintos tipos de formas jurídicas, así como también distintos ciclos del proceso económico, que incluyen no sólo la producción sino también, el crédito, la distribución, la comercialización y el consumo.

\section{4.- La disposición a la innovación social por parte de las iniciativas de la economía social y solidaria}

Defourny y Nyssens (2013) resaltan algunas cuestiones clave respecto la dimensión económica y emprendedora de las empresas sociales que són aspectos útiles para encuadrar y entender la disposición a la innovación por parte del sector. Entre estas cuestiones se puede destacar la preocupación continua por la producción de bienes y venta de servicios, desde una perspectiva genuinamente productiva. Ante un contexto macroeconómico en que la economía especulativa ha colonizado los mercados denigrando el valor productivo de la actividad financiera, la economía social se reivindica a si misma por el hecho de plantear la actividad económica y en especial la emprendeduría como una cuestión vinculada de raíz a la economía productiva. El directorio de iniciativas empresariales que per- 
tenecen a la Xarxa d'Economia Solidària de Catalunya, permite el análisis por sectores productivos con los siguientes epígrafes: producción agrária; producción industrial y construcción; comercio; servicios a las personas; servicios a empresas; servicios ambientales; servicios de comunicación; servicios financieros; servicios sociales y culturales; cooperación y educación para el desarrollo; y otros. Esto nos ofrece una visión del sector como las prácticas centradas en recuperar el valor productivo de la economía haciéndolo compatible con objetivos democratizadores, en pro de la justicia social, el tratamiento y la transformación de las dinámicas de exclusión social y la responsabilidad ambiental. Por otra parte, en el mismo sentido, el análisis de los proyectos financiados por entidades bancarias que actúan con criterios vinculados a la economía solidaria y se encuadran en lo que se denomina banca ética, se rige especialmente por este mismo reto ambicioso de combinar actividad productiva y fomento de la democracia. Los proyectos financieros enmarcados dentro de la banca ética se distinguen por el principio de ayudar únicamente a prácticas económicas con un retorno socioecológico y de carácter no especulativo.

Otra dimensión típica que caracteriza las iniciativas de economía social en general, según Defourny y Nyssens (2013) es el hecho que asumen un grado considerable de riesgo económico. El hecho de contar con el esfuerzo de los trabajadores y/o miembros de las iniciativas para asegurar su desarrollo es importante así como contar con el apoyo de las Administraciones públicas para superar los riesgos con los que se enfrentan. Un ejemplo significativo en este sentido son las empresas de inserción que han abordado el cambio de sector de actividad de modo satisfactorio, como es el caso de Fundació Futur $^{3}$ en Barcelona, que en su momento pasó de los manipulados electrónicos a la restauración saludable; o las entidades que surgen de procesos de apropiación y recuperación de empresas en quiebra por parte de los propios trabajadores como es el caso de la histórica cooperativa metalúrgica catalana Mol Matric ${ }^{4}$.

Como hemos afirmado anteriormente en un contexto post-fordista la economía social y solidaria pone de relieve la necesidad y la existencia de medios para la democratización de la economía. Esto implica que todo el conjunto de actividades que se encuentran en el marco de la economía social y solidaria son actividades a considerar con atención en el desarrollo de respuestas a los problemas que emergen como retos sistémicos en un contexto de crisis multidimensional. Son prácticas económicas especialmente idóneas tanto por lo que respecta al desarrollo de partenariados de actores en la provisión de servicios de bienestar local como para responder a las necesidades de modelos de desarrollo económico integrados territorialmente. Es por esto que podemos afirmar que el papel de la economía social y solidaria en las políticas de desarrollo local y promoción económica es seguramente una de las cuestiones que la actual crisis sistémica pone de nuevo de relieve. Varios son los autores que han trabajado la relación entre la difusión de la economía social y la globalización, anticipando el

3.- Disponible en http://www.futur.cat/es/ acceso el: 25/07/2016.

4.- Disponible en http://www.molmatric.coop/mo/ acceso el: 25/07/2016. 
análisis de las respuestas de las prácticas económicas solidarias a las múltiples crisis simultáneas que vivimos en la actualidad (Antuñano y González, 2012; Bauhardt, 2014; Boulianne et al., 2003; Coque et al., 2012; Dubois y Lasida, 2010; Inglada y Sastre, 2014).

Desde 1996 con la creación de la red de investigación sobre economía social EMES5, existe en Europa una conciencia alrededor de la importancia que han tenido las organizaciones del tercer sector en el desarrollo de nuevos tipos de servicios que tomaran en consideración los retos sociales de su tiempo. Para Defourny y Nyssens (2013) es evidente que las Administraciones públicas han promovido el desarrollo del tercer sector durante las tres últimas décadas buscando proveedores privados que ofrecieran unos servicios y soluciones que las Administraciones hubieran desarrollado ellas mismas si hubieran contado con la disposición a la redistribución que tuvieron en el periodo de desarrollo del Estado del bienestar keynesianista (1945-1975).

Según Defourny y Nyssens (2013) el desarrollo de las empresas sociales responde a nuevos productos o a una nueva calidad de productos; nuevos métodos de organización y/o producción; y nuevos factores de producción. En muchos casos las empresas sociales o las entidades del tercer sector social se caracterizan por estar vinculados a áreas complementarias de los servicios sociales básicos, o por ser empresas resultantes de la adaptación a nuevas necesidades como son la atención a la infancia, los servicios para la gente mayor, el fomento de la formación profesional, o la ayuda a determinados sectores de población vulnerable. Esta orientación a áreas complementarias de los servicios sociales básicos incide en su caracterización como iniciativas que ofrecen respuestas a necesidades sociales no resueltas por la Administración pública.

El carácter subsidiario o derivado de otros servicios y recursos públicos vincula la actividad de una gran parte de la economía social a su orientación mercantil, o de solución comercial que complementa a los recursos o servicios que ofrece el Estado o el mercado. Es una cuestión que tiene un lugar preponderante en ciertas perspectivas teóricas respecto a cómo podemos definir la noción de innovación social de modo similar al enfoque del debate sobre lo que es y debería ser el tercer sector y la economía social. La tendencia de raíz anglosajona a reseguir la economía y la innovación social alrededor de los usos y actividades comerciales por parte de organizaciones no gubernamentales entronca con esta cuestión. Es la perspectiva sobre la innovación social que también se preocupa por las actividades comerciales de entidades sin ánimo de lucro o los esquemas de explotación comercial que responden a una misión social.

Cuando hablamos de los nuevos métodos de organización y gestión de la producción en las empresas sociales aparece una característica común ya apuntada que es la implicación de distintos tipos de actores. Esta implicación de actores con distintas naturalezas, tipos de compromiso y sistemas de funcionamiento caracteriza a las empresas sociales como organizaciones más híbridas en comparación a concepciones típicas de las empresas tradicionales en la que la toma de la decisiones tendía

\section{5. - Disponible en http://emes.net acceso el: 25/07/2016.}


a estar restringida a uno o dos tipos de actores. En las empresas sociales los tipos de actores que pueden formar parte de los consejos rectores son múltiples y diversos. Un ejemplo de esto es la presencia de personas usuarias o beneficiarias de los servicios en los órganos de toma de decisiones en muchas empresas sociales. En el sino de muchas empresas sociales los usuarios ya no son considerados como simples consumidores o clientes sino que son involucrados como actores centrales del desarrollo del servicio en si mismo. Un ejemplo en este sentido lo ofrecen las entidades de servicios comunicativos que promueven proyectos de periodismo crítico como el Setmanari La Directa6, Diagonal ${ }^{7}$ o Sentit Crític ${ }^{8}$. Estos proyectos cooperativos enmarcados dentro del movimiento ciudadano en favor de la economía solidaria, se basan en la concepción de sus usuarios como "prosumidores" promoviendo su participación en la generación de contenidos, en la toma de decisiones y en la promoción del proyecto como herramienta de empoderamiento ciudadano.

Siguiendo a Levesque (2013) esta misma transformación de la calidad de consumidores a usuarios, co-productores o ciudadanos "prosumidores", también se puede identificar con el nuevo paradigma en el que las políticas públicas y la Administración debe pensar la relación con la ciudadanía y el desarrollo de los recursos y servicios públicos. Para Levesque la innovación social conlleva un nuevo paradigma en los sistemas de gestión públicos, superando las premisas de la nueva gestión pública de corte neoliberal, que se basa en la consideración del cambio de rol de la ciudadanía, que deja de ser consumidora pasiva de los recursos y servicios públicos para ser coproductora de estos.

Analizando los nuevos modelos de organización de las entidades del sector Garcia Jané (2014) realiza un listado de tendencias emergentes que se pueden identificar en muchas de las prácticas de la economía social y solidaria. Ese listado es paradigmático de los elementos que marcan el debate sobre lo que son procesos de innovación social aplicados a las organizaciones en general ya que se trata de aspectos que afectan todo tipo de entidades, y no solo las pertenecientes al sector de la economía social y solidaria. El uso intensivo de Internet ha permitido mejorar la efectividad, la eficacia y la eficiencia de muchas prácticas económicas promoviendo una revolución en todos los ciclos del proceso económico. En esta dirección si que es verdad que la voluntad de contribuir al trabajo en código abierto y al procomún, -objetivos coincidentes con los valores de la democratización económica-, es especialmente visible en el sector solidario con la adopción de dinámicas de proveimiento participado (crowdsourcing), que se pueden observar por ejemplo en la construcción colaborativa del mapa de la economía solidaria catalana, Pam a $\mathrm{Pam}^{9}$, promovido por Setem y la XES.

Otra tendencia señalada por Garcia Jané es la hibridación de fórmulas organizativas buscando complementariedades y beneficios en el uso de distintas fórmulas jurídicas que permitan la incorporación de diferentes tipos de actores (multistakeholder). Esta tendencia es muy común entre plataformas ciudadanas que dinamizan espacios en los que se llevan a cabo actividades socioculturales, y

6.- Disponible en http://directa.cat acceso el: 25/07/2016.

7.- Disponible en http://www.diagonalperiodico.net acceso el: 25/07/2016.

8.- Disponible en http://www.elcritic.cat/ acceso el: 25/07/2016.

9.- Disponible en http://pamapam.org/ca acceso el: 25/07/2016. 
promueven, de modo paralelo a las asociaciones culturales que sirven de plataforma ciudadana gestora de la iniciativa, cooperativas de trabajo encargadas de la gestión de recursos clave para los equipamientos como puede ser el servicio bar.

También cabe señalar la tendencia al cada vez mayor consumo cooperativo de bienes y servicios, así como de espacios y recursos, entre personas, entidades y empresas. Un ejemplo de esto puede ser la proliferación de grupos cooperativos, como es el caso del grupo ECOS ${ }^{10}$ en Barcelona, en el que distintas empresas, entidades y profesionales con puntos en común tanto en su ideario como entre sus áreas de actividad, comparten espacios y generan dinámicas de colaboración en sus formas de producción y consumo.

La importancia otorgada al enraizamiento territorial de las iniciativas es otro de los aspectos que siendo una característica importante en el marco de la nueva economía en general lo es en especial entre las iniciativas del sector solidario. Como ejemplos de esta tendencia cabe señalar la dinámica a la construcción de redes locales de intercambio y soporte mutuo en aquellos territorios donde el sector tiene una presencia considerable. Esto se vincula a otra tendencia innovadora que es la inmersión de los proyectos en redes, entornos o ecosistemas cooperativos, que sin participar directamente con responsabilidades en la gestión o los resultados participan de su promoción y dinamismo. Los casos de la plataforma Sants Barri Cooperatiu ${ }^{11}$ o CooperaSec ${ }^{12}$ en Barcelona, o Benimaclet Cooperatiu 13 en València, son proyectos que con distintos grados de madurez promueven el desarrollo local y la popularización de la economía comunitaria con una perspectiva local a escala de barrio.

Por otro lado Garcia Jané (2014) señala otras tendencias como: el énfasis en la construcción de comunidades alrededor de las prácticas económicas como factor que favorece la intraemprendoria; el uso de formas híbridas de financiación en las que tienen mucha importancia la multiplicación de pequeñas cantidades de capital; o el carácter de la multiactividad, -esto quiere decir el hecho que los modelos empresariales en cuestión dentro del sector tienden cada vez más al desarrollo de diversas actividades a la vez para ser sostenibles económicamente- (Garcia Jané, 2014: 33). La consideración de todas estas características son clave en el momento de promover políticas públicas orientadas a estimular el sector.

Como se ha apuntado anteriormente, según Defourny y Nyssens también es importante señalar la existencia de nuevos factores de producción en el si de las entidades que se denominan como empresas sociales. Estas nuevas condiciones de producción hacen referencia a que el trabajo voluntario ha cambiado profundamente. El rol del voluntariado en el si de las entidades del tercer sector, así como en el sino de los movimientos sociales o el asociacionismo sociocultural, se ha transformado.

10.- Disponible en http://www.grupecos.coop/cat acceso el: 25/07/2016.

11.- Disponible en http://sants.coop acceso el: 25/07/2016.

12.- Disponible en http://cooperasec.barripoblesec.org acceso el: 25/07/2016.

13.- Disponible en https://barricoop.org/ acceso el: 25/07/2016. 
El principal cambio es cualitativo y se refiere a un tipo de ejercicio menos caritativo, en el sentido de más centrado en los procesos de emancipación y en el apoderamiento de personas y grupos sujetos a dinámicas de exclusión. También sería un rol más condicionado que lo que había sido la militancia durante la segunda mitad del siglo veinte. En la actualidad las organizaciones del sector social tratan con personas que ofrecen su trabajo voluntario condicionando su participación a objetivos productivos concretos y a actividades que se corresponden con sus necesidades específicas o intereses ideológicos puntuales. También en este sentido es señalado como usual que el rol de emprendedor estratégico dentro de las organizaciones sea desarrollado por personas voluntarias.

Otra cuestión importante que también tiene que ser considerada en el capítulo de transformaciones de los factores de producción de las empresas sociales es el hecho que el trabajo remunerado en el si de las empresas sociales se ha visto condicionado por la influencia de las políticas públicas. Sin duda la promoción de esquemas de subvención de la contratación dentro del marco de las políticas públicas de empleo en programas de reducción del paro condiciona la capacidad de decisión de las entidades del sector social en la naturaleza, duración, y calidad de la contratación que ofrecen. Muchas empresas del tercer sector han estado experimentando las vicisitudes de su implicación en el desarrollo de políticas públicas de empleo.

\section{5.- Promoviendo la divulgación de unas prácticas económicas difíciles de parametrizar}

En este apartado analizamos las vicisitudes de la divulgación de las prácticas económicas de carácter social y solidario, como un primer paso en el desarrollo de políticas públicas para su fomento. Siguiendo los mecanismos contenidos en la Tabla 1, el apartado atiende a la producción de eventos de sensibilización, a las cuestiones relacionadas con el estudio y parametrización del sector, y a la promoción de iniciativas específicas entre gestores y responsables políticos de la Administración pública, entendiendo que cada una de estas estrategias cuenta con sus retos y vicisitudes particulares. 


\section{Tabla 1. Tipos de estrategias de divulgación de las prácticas de la economía solidaria identificadas en el contexto de la provincia de Barcelona entre 2012 y 2016}

\begin{tabular}{|l|l|}
\hline Estrategia & Retos y dificultades \\
\hline Eventos de sensibilización ciudadana & $\begin{array}{l}\text { Evitar la folclorización del sector y promover una sensibilización cotidiana, } \\
\text { no eventual o vinculada a momentos de excepcionalidad. }\end{array}$ \\
\hline Estudio y parametrización del sector & $\begin{array}{l}\text { Complejidad analítica en la delimitación del sector social y solidario. } \\
\text { Importancia del diagnóstico participado con el sector y de la toma en } \\
\text { consideración de su naturaleza multidimensional y gradual. }\end{array}$ \\
\hline $\begin{array}{l}\text { Divulgación entre cargos electos y gestores } \\
\text { de políticas públicas }\end{array}$ & $\begin{array}{l}\text { Es importante promover conocimiento sobre la diversidad y } \\
\text { complementariedad entre iniciativas. } \\
\text { Riesgo de sectorialización de la política de fomento de la economía } \\
\text { solidaria, perdiendo la transversalidad que debe tener la incorporación de } \\
\text { los principios de democratización económica. }\end{array}$ \\
\hline
\end{tabular}

FUENTE: Elaboración propia.

Una de las estrategias más comunes en favor de las entidades, estrategias e iniciativas que se orientan al fomento de la economía social y solidaria es la organización de eventos y actividades que implican la movilización colectiva de actores de distintos sectores mediante encuentros foros 0 exhibiciones colectivas que ponen de relieve el papel y las funciones de este conglomerado de actividades socioeconómicas plural y heterogéneo. Según Fraisse (2013) en Francia en 2011 se contabilizaron 1700 eventos repartidos por todo el Estado francés vinculados a la sensibilización ciudadana alrededor de la economía social y solidaria. La producción de eventos, ferias y festejos alrededor de las formas alternativas de producción consumo y distribución de recursos es una manera evidente de promover el cambio cultural mediante la sensibilización ciudadana al respecto de la existencia de alternativas a las opciones de actividad económica hegemónicas. La escalabilidad y replicabilidad de esta estrategia es evidente, puesto que no requiere de grandes inversiones ni implica grandes cambios en las formas de funcionar de las Administraciones públicas. Las Administraciones municipales se pueden plantear su eventual promoción en un momento determinado sin por ello producir grandes cambios en sus formas de proceder o de interactuar con la ciudadanía organizada. Un ejemplo reciente de este tipo de abordaje es la organización por parte del Ayuntamiento de Barcelona de la Fira de Consum Responsable, Economia Social i Solidària de Barcelona, en la Plaza Catalunya, que se celebró por primera vez durante las navidades de 2015, justo unos meses después del cambio de gobierno municipal en favor de Barcelona En Comú.

La crítica que se puede hacer desde el propio sector a esta estrategia concreta de promoción pública es que contiene un riesgo evidente de folclorización de la actividad de la economía social y solidaria. Convertir las estrategias socialmente innovadoras en animales de feria sería la caricatura a la que podríamos llegar si centramos nuestra estrategia de promoción pública de la innovación social y de la economía social y solidaria únicamente en la producción de eventos de sensibilización. 
Otra estrategia que supone un paso más allá en la producción del cambio cultural necesario vinculado a la economía social y solidaria, y que pueden promover las Administraciones públicas a través de sus políticas, es la visualización y divulgación de indicadores económicos que faciliten la comprensión por parte de la ciudadanía de su importancia. Esta se trata de una estrategia que requiere divulgar prácticas e indicadores de análisis socioeconómico, y por lo tanto no siempre se puede considerar como una estrategia disponible o útil para todo tipo de Administraciones o servicios técnicos de las Administraciones públicas. El Ayuntamiento de Barcelona, en enero de 2016 dió a conocer el estudio L'economia social i solidària a Barcelona (2016) que ensaya una aproximación en este sentido. El estudio realizado por Anna Fernández i Ivan Miró, miembros de la cooperativa La Ciutat Invisible ${ }^{14}$, contabiliza unas 4.718 iniciativas del sector en la ciudad, representando más de 53.000 personas contratadas que corresponden a un 8\% de la población ocupada (Fernández \& Miró, 2016).

La cuantificación del volumen de negocio de las empresas vinculadas a la economía social y solidaria, el número de organizaciones, el número de trabajos generados, el porcentaje de creación de empleo o los sectores implicados en una región o en una área urbana son datos que podrían tener una presencia mucho más relevante en la esfera pública. Garcia Jané (2014) estima la magnitud de la economía social y solidaria en Catalunya alrededor de los 130.000 lugares de trabajo representando un $4,6 \%$ de la población ocupada, contabilizando unas 27.000 empresas y entidades, que pueden relacionarse con el sector, siempre de manera orientativa y con distintos tipos de intensidad o compromiso con los principios descritos. Fraisse, por su lado, destaca que del 7 al $13 \%$ de las organizaciones empresariales y el empleo en el Estado francés podría pertenecer a la economía social y solidaria (Fraisse 2013). La parametrización y el seguimiento cuantitativo de este sector es un campo todavía por explorar por parte de las Administraciones públicas, así como por parte del mundo académico, o el propio sector. Desde el ámbito académico, con un enfoque más o menos cuantitativista, son diversos los estudios que se han orientado a ofrecer aproximaciones en este sentido (Arrieta 2014; Chaves, 1997; Chaves et al. 2013; Díaz y Marcuelo, 2010; Garcia Müller, 2012; Monzón 2006; Vaillancourt 2011). En este empeño cuantitativo investigadores como Isabel Vidal (2008) han desarrollado el estudio del sector a partir de los datos derivados del directorio general de empresas del Instituto Nacional de Estadística español, relacionando al sector social, con unas formas jurídicas determinadas. Pero se trata de una fuente de información que solo puede ofrecer valores aproximativos pues no permite profundizar en indicadores inequívocos sobre la gobernanza democrática de las organizaciones empresariales. Estudiar la magnitud cuantitativa de la economía social y solidaria tiene dificultades metodológicas considerables que el propio sector procura solucionar mediante un abordaje cualitativo con la promoción de balances sociales o sellos de reconocimiento, como es el caso de la plataforma Ensenya el cor ${ }^{15}$ de la propia Xarxa d'Economia Solidària de Catalunya.

14.- Disponible en http://www.laciutatinvisible.coop acceso el: 25/07/2016.

15. - Disponible en http://ensenyaelcor.org/ acceso el: 25/07/2016. 
En términos de políticas públicas, el desarrollo de indicadores para hacer seguimiento de este tipo de organizaciones empresariales está por explorar y podría ser operativo sobretodo en las escalas de gobernanza de ámbito regional, en las grandes ciudades o en los consejos y diputaciones de tipo supramunicipal. En este sentido es destacable el papel que está teniendo la Diputación de Barcelona, -en tanto que entidad que ofrece asesoramiento a servicios técnicos municipales-, en la popularización del sector y en el desarrollo de actividades de seguimiento y divulgación de la utilidad de sus prácticas como herramientas de las políticas locales de dinamización económica.

También en este aspecto cabe señalar que es importante de qué modo se promueve desde las Administraciones públicas un cambio en los medios de comunicación respecto al cómo estos ofrecen información de tipo socioeconómico. 0 sea, una parte de la innovación social se juega en el terreno sociocultural y en la construcción del lenguaje utilizado para tratar los retos sociales. La cuestión de la visualización de los efectos socioeconómicos de las entidades, estrategias e iniciativas empresariales vinculadas al sector social y solidario es cada vez una cuestión más ineludible por parte de los medios de comunicación de masas, si tenemos en cuenta también los efectos que tiene en la definición de sus contenidos la irrupción de las redes sociales y la autocomunicación de masas.

Una tercera línea estratégica que pueden seguir las Administraciones públicas en favor de la divulgación de la economía social y solidaria es la promoción específica del conocimiento de iniciativas concretas de innovación social. En este sentido Fraisse (2013) hace referencia a las actividades orientadas a divulgar la pluralidad de iniciativas que conforman el sector entre los cargos electos y los gestores de políticas públicas. De nuevo aparece como una cuestión importante la sensibilización, considerada en este caso como el fomento del descubrimiento e intercambio de experiencias en funcionamiento que actúen como casos de éxito en la que los representantes políticos así como los agentes que participan en la toma de decisiones políticas se puedan reflejar.

Uno de los principales retos divulgativos de la actividad de la economía social y solidaria es el fomento del conocimiento de la diversidad de iniciativas que implica. Trascender la identificación de la economía que funciona por parámetros de utilidad social como una cuestión marginal muy asociada a la beneficencia, al asistencialismo, a la lucha contra el paro y la pobreza por parte de entidades sin ánimo de lucro asociadas al tercer sector es el reto en este sentido. Entender que la diversidad de iniciativas vinculadas a prácticas económicas con criterios de transformación y justicia socio-ecológica abarcan todos los sectores de actividad así como todas las prácticas asociadas a la esfera económica es una cuestión clave.

Como ha destacado ámpliamente la literatura sobre democratización económica el consumo, la producción, la distribución y el crédito, son prácticas susceptibles de ser realizadas con criterios éticos determinados. La divulgación sobre la existencia de una heterogeneidad de iniciativas, que, operando con principios de autonomía y cooperación, se complementan las unas a las otras es el punto relevante en esta cuestión. Seguramente una de las cosas en el ámbito de la divulgación que pueden hacer las Administraciones públicas al respecto de la economía social y solidaria reside en visualizar 
la complementariedad existente entre entidades de distinto tipo dentro del marco conceptual de las actividades económicas que promueven la gobernanza democrática. Esto tiene un sinfín de puntos de abordaje divulgativos que pueden depender en cada caso de las realidades empresariales con las que se encuentran las Administraciones en su territorio. Mostrar la relación entre el fomento del consumo responsable y desarrollo económico; el papel de la producción con criterios de responsabilidad socioecológica respecto a la dinamización de su entorno y las relaciones sociales que se producen en él; la posibilidad de una distribución de recursos y servicios no especulativa y colaborativa que reduzca ineficiencias y suponga la transición hacia una economía verde o circular; o la posibilidad de un uso de las finanzas de carácter alternativo al hegemónico, que sea antimilitarista o que se plantee mecanismos para promover la no supeditación de las personas a los intereses financieros, son las líneas argumentativas generales que pueden tener derivadas muy concretas en función de las realidades de cada territorio. Los pétalos de la flor de la economía social y solidaria, o las hojas del olmo que la sostiene, siguiendo la metáfora de Garcia Jané (2012), son muchas y su floración no puede seguir el mismo sentido o patrón en todos los territorios, debe adecuarse pues a sus realidades pre-existentes.

\section{6.- Medidas públicas y estímulos administrativos en favor de la economía social y solidaria}

Más allá del fomento de la divulgación y la sensibilización ciudadana existen distintas estrategias para promover de modo directo la actividad económica de proyectos concretos que son especialmente aplicables por parte de las Administraciones municipales. Como se puede observar en la Tabla 2, las medidas públicas y los estímulos administrativos en favor de la economía social y solidaria pueden incluir: el fomento de concursos públicos o bolsas de financiación para promover la provisión de servicios según las necesidades locales; el impulso de redes de intercambio y monedas sociales; el soporte a espacios de dinamización sociocomunitaria en los que se vincule ciudadanía y desarrollo local; el desarrollo de cláusulas sociales en los contratos de la administración; y también el estímulo administrativo a la transformación de los modelos empresariales hegemónicos en el ámbito privado. 


\section{Tabla 2. Tipos de medidas públicas y estímulos administrativos en favor de la economía social y solidaria identificados en municipios de la provincia de Barcelona entre 2012 y 2016}

\begin{tabular}{|l|l|}
\hline Medida & Descripción \\
\hline $\begin{array}{l}\text { Bolsas de financiación para emprendedores } \\
\text { sociales }\end{array}$ & $\begin{array}{l}\text { Destinado a pequeñas iniciativas en fase de desarrollo. } \\
\text { Útil como mecanismo de busca de proveedores que den respuesta a } \\
\text { necesidades locales. }\end{array}$ \\
\hline $\begin{array}{l}\text { Apoyo a espacios de dinamización } \\
\text { socio-comunitaria }\end{array}$ & $\begin{array}{l}\text { Espacios que promueven la sensibilización y el aprendizaje } \\
\text { colaborativo entorno los retos de desarrollo local. } \\
\text { Fomento de la intersección entre iniciativas empresariales y prácticas de } \\
\text { ciudadanía. }\end{array}$ \\
\hline $\begin{array}{l}\text { Redes de intercambio de recursos y servicios } \\
\text { (Impulso a monedas locales complementarias) }\end{array}$ & $\begin{array}{l}\text { Mecanismo para hacer frente a la pérdida de valor de las economías locales, } \\
\text { promover la activación laboral y la dinamización del comercio local. }\end{array}$ \\
\hline administración & $\begin{array}{l}\text { Incorporación de criterios sociales y medioambientales en los pliegos de } \\
\text { contratación tanto en la fase de admisión como de valoración de las } \\
\text { ofertas y condiciones de ejecución. } \\
\text { Herramienta normativa con múltiples temáticas en las que desarrollar } \\
\text { aplicaciones posibles. }\end{array}$ \\
\hline $\begin{array}{l}\text { Estímulos administrativos a la transformación } \\
\text { empresarial }\end{array}$ & $\begin{array}{l}\text { Exhortación a la mejora de aspectos sociales, económicos o ecológicos en } \\
\text { las prácticas empresariales del sector privado mediante el ofrecimiento de } \\
\text { incentivos administrativos en los servicios y recursos ofrecidos por parte de } \\
\text { la Administración. }\end{array}$ \\
\hline
\end{tabular}

FUENTE: Elaboración propia.

Uno de los mecanismos más frecuentes de estímulo del sector son los concursos públicos o bolsas de financiación para emprendedores diseñados con criterios específicos para que los procedimientos de resolución apunten directamente a prácticas de economía social y solidaria en general, 0 a la resolución de necesidades sociales específicas de un determinado contexto territorial. Esta estrategia es útil para ofrecer impulso a pequeñas iniciativas o proyectos en fase de desarrollo que coincidan con intereses particulares de las Administraciones dependiendo de su escala gubernativa y territorio de referencia. También es útil en tanto que mecanismo para la búsqueda de proveedores de servicios que ofrezcan respuestas a problemáticas locales concretas. En Barcelona esta estrategia se ha seguido en la organización del Social Start-Up meeting, promovido por la Universidad de Barcelona, con la colaboración de distintas entidades del sector cooperativo y el respaldo de las Administraciones.

El fomento de redes del intercambio de recursos y servicios mediante canales alternativos al sistema monetario convencional representa otra área de acción posible para las Administraciones. Entre otras cosas, esta línea de acción es la que puede identificarse con el impulso de monedas sociales y ha captado la atención de una literatura específica con numerosas referencias bibliográficas orienta- 
das al análisis en detalle de monedas alternativas y sus efectos en el desarrollo económico de territorios (Crespo y Sabín 2014; Dini 2012; Paolo y Kiopkiolois 2014; Place y Bindewald 2015). Las monedas sociales pueden tener orígenes autónomos dentro de la sociedad civil, no promovido específicamente por las Administraciones, y representar redes de solidaridad articuladas por la ciudadanía para esquivar los efectos de la escasez de trabajo y recursos financieros. También pueden ser promovidas o institucionalizadas por las Administraciones como maneras de hacer frente a la pérdida de valor de las economías locales, como se demuestra en distintos ayuntamientos que utilizan la proyección de monedas locales como mecanismo de activación de empleo, de dinamización del consumo de proximidad y de impulso al comercio local, entre otros objetivos. Baviera, Bristol o Toulousse, han desarrollado monedas regionales que en la actualidad están sirviendo de referente a muchas municipalidades del contexto europeo que se plantean su impulso en un futuro próximo.

Por otro lado cabe señalar el apoyo a espacios de dinamización sociocomunitaria como un elemento clave de las políticas públicas en favor de la democratización económica. En este sentido la consolidación de agencias de desarrollo local como centros de dinamización sociocomunitaria es una demanda articulada por el sector. Esta cuestión subraya la consideración del vínculo posible entre las políticas de fomento de la activación laboral con la articulación de respuestas empresariales de tipo comunitario, social y solidario. También se puede observar en este aspecto el cambio estratégico en las políticas de promoción empresarial del énfasis propio de los años noventa del siglo veinte en la promoción pública de "incubadoras empresariales" entendidas como oficinas alquiladas a bajo coste para empresas que arrancan, a la consideración estratégica del apoyo de espacios de trabajo compartido (coworking), ya más distintiva de la innovación empresarial en el siglo XXI, entendidos como espacios de aceleración en los que el valor de las dinámicas entre iniciativas empresariales distintas es muy importante. La necesidad de espacios para la promoción económica que faciliten la proximidad con la ciudadanía es contemplada por la propia Xarxa d'Economia Solidaria de Catalunya, en sus recomendaciones de medidas para el fomento del sector a nivel municipal (XES, 2015). En este caso, de nuevo, la aparición de una preocupación pública por el fomento de espacios de dinamización sociocomunitaria como un recurso que tiene un valor económico para los territorios se identifica plenamente con la retórica de la innovación social.

Una estrategia más directiva, en el sentido de pretender unos efectos más inmediatos, son las llamadas cláusulas sociales, que como elemento clave en el fomento de la economía social y solidaria y también en las políticas de activación de empleo e inclusión social cuentan con una literatura específica asociada (Bernete, 2013; Paniagua Zurera, 2013; Primavera, 2010; Ruiz, Retolaza y Mugarra, 2007; Valor, 2006). La introducción de cláusulas sociales se basa en la alteración de las rutinas de la Administración y los métodos para el anuncio, la valoración y la selección de proyectos socioeconómicos en los contratos de la Administración. La incorporación de criterios sociales y medioambientales en los pliegos de contratación tanto en la fase de admisión como de valoración de las ofertas y condiciones de ejecución ofrece múltiples aplicaciones, tanto en el fomento de la activación laboral de colectivos con difícil inserción, como en el fomento del comercio justo, ya ha sido aplicada en muchas municipalidades, como demuestra Juan Bernete (2013:85). Esta herramienta administrativa, -que sin 
duda puede actuar como una medida estratégica para la promoción de la economía social y podría ser desarrollada en todos los niveles y escalas de las Administraciones públicas-, se puede articular con el objetivo de integrar los principios de la economía social y solidaria tanto como sea posible y del modo más transversal en todas las fases de las políticas y procesos de desarrollo socioeconómico promovidos por la Administración. Es sin duda por contra una medida que despierta controversia por parte de aquellos actores e iniciativas empresariales que están acostumbrados a trabajar con la contratación pública de un modo regular y cotidiano sin por ello responder a criterios que se puedan enmarcar en los principios de la economía social y solidaria. Los ejemplos de prácticas en este sentido son múltiples, implican distintos ámbitos de aplicación, y se puede considerar como una práctica que está en plena evolución. Es significativo de esta evolución por ejemplo el reciente compromiso de municipios como Barcelona, Mataró, Sant Cugat del Vallès, Olot, Vilanova y la Geltrú, el Vendrell, Castelló de la Plana y Tarragona, a rechazar el establecimiento de contratos públicos con empresas que tengan filiales en paraísos fiscales (Blanchar, 2016).

La definición de cláusulas sociales y ambientales en los criterios de adjudicación y compra en los mercados públicos es una medida importante para promover el desarrollo de estrategias socialmente innovadoras alrededor de empresas proveedoras de servicios o recursos con criterios de responsabilidad social. Para su aplicación en algunos casos es necesario la adaptación de las órdenes y concursos de adjudicación de compras públicas para que respondan a las medidas y el tamaño de las empresas sociales. En otros casos, dependiendo del sector de actividad implicado, requiere el cambio en la escala de la oferta aportando soporte técnico a los productores locales para que puedan responder a las necesidades de la Administración. Esto desde la perspectiva práctica de las Administraciones implica inversión en servicios técnicos de promoción empresarial y desarrollo económico que ayuden al desarrollo de la oferta de estas empresas. Una cuestión que puede llevar a la creación de partenariados o asociaciones de tutelaje entre Administraciones públicas y negocios locales considerando las necesidades particulares del territorio. Un ejemplo de ofrecimiento de soporte técnico por parte de la Administración para el arranque de una iniciativa del sector lo ofrece el Ayuntamiento de Manlleu (Barcelona) con el desarrollo de la empresa de inserción Sambucus ${ }^{16}$. Esta entidad ha sido promovida respondiendo a necesidades detectadas por la Administración Municipal con un proyecto que vincula inserción sociolaboral de colectivos desfavorecidos, agricultura ecológica, y restauración, y responde a la necesidad de dinamizar el restaurante del mercado municipal, y pese a que tiene una naturaleza independiente de la Administración, sin el papel clave de los técnicos y responsables políticos municipales en la fase de desarrollo del proyecto no se comprendería su funcionamiento.

Finalmente otra cuestión importante es el modo en que las Administraciones pueden promover el cambio organizacional de las empresas configuradas según el modelo hegemónico tradicional propio del capitalismo de mercado, mediante el condicionamiento de la ayuda para el desarrollo económico o empresarial, con criterios de responsabilidad social, ecológica y de compra responsable. Ejemplos 
llevados a término de este tipo de estímulo son los casos de Administraciones que exhortan a las empresas con las que tienen trato a mejorar sus prácticas en términos de participación de los trabajadores en la gobernanza corporativa y los esquemas de repartimiento de beneficios, o en el desarrollo de puestos de trabajo vinculados a las necesidades del entorno social en el que se encuentran. En este aspecto el modo en que el sector avance en la definición de auditorías y balances sociales que indiquen de modo práctico cómo se puede concretar la responsabilidad y la transparencia empresarial es crucial también para su posicionamiento, como distintos autores ya han destacado (Pérez, 2013; Ruiz y Retolaza 2005; Socias y Horrach 2013).

\section{7.- Conclusiones: Hacia unas políticas de promoción económica comprometidas con la gobernanza democrática}

La primera cuestión que plantea la revisión general de las estrategias con las que cuentan las Administraciones públicas, y más concretamente la escala de gobierno municipal, en favor de las iniciativas de la economía social y solidaria es que son políticas que tienden a centrarse principalmente en la emergencia de nuevas prácticas y iniciativas a nivel local. Esta observación pone de relieve que el desarrollo de una economía con criterios sociales y formas de funcionar democratizadoras que vayan más allá de la lógica competitiva del beneficio propio, requiere también del desarrollo de políticas de fomento de la democratización de la economía a nivel estatal o Europeo. La principal objeción en este sentido es que el sector social y solidario no representa una oposición seria a los actores económicos globales, puesto que su desarrollo e implantación está muy limitada al nivel local en el que todos los criterios y condicionantes de una economía a escala humana son manejables. Este aspecto plantea indirectamente una de las críticas más profundas y extendidas a las retóricas alrededor de la necesidad de innovación social en el contexto de la economía del conocimiento del siglo veintiuno. Muchas veces la innovación social es presentada como una acumulación de cambios a nivel micro y sus políticas de fomento se basan en la diseminación de buenas prácticas más que en el desarrollo de cambios estructurales de las reglas que rigen la competición entre actividades económicas a nivel macro. En este sentido una cuestión importante para la literatura que analiza los retos del sector social comprometido con la economía social y solidaria es la superación de la trampa del localismo. La necesidad de implicarse en los sistemas de gobernanza multinivel a escala europea es una cuestión que redes como la EMES o RIPESS ${ }^{17}$ toman en consideración, y que pueden rescatar el sentido social y progresista de la gobernanza a nivel europeo promoviendo el cambio en las estructuras de los Estados nación en favor de posturas comprometidas a nivel macroeconómico con el fomento de la economía social y solidaria. De momento la realidad está muy lejos de esto. 
Otra cuestión que se pone de relieve en la discusión entorno a las políticas de fomento de la economía social y solidaria es el riesgo de institucionalizar un nuevo nicho de actividad para las políticas públicas, promoviendo la creación de políticas específicas con programas periféricos dentro del conglomerado de proyectos que componen las políticas sociales. En este caso es importante destacar, como se ha hecho a lo largo del artículo, la transversalidad e integralidad de las políticas de promoción de este tipo de prácticas económicas. La superación de la Administración pública dividida en compartimientos estancos sin conectividad, o con la mínima intercooperación entre ellos, es uno de los retos que las narrativas de la innovación social del siglo veintiuno plantean por lo que respecta a los sistemas de gestión públicos.

Los vínculos entre las aproximaciones a la economía solidaria y determinadas de las aproximaciones a la noción de innovación social son innegables desde el momento en que ambas perspectivas se orientan a la cuestión de proveer de valor social a la actividad económica. La divulgación sobre indicadores de la gobernanza democratizadora de las iniciativas públicas, así como de prácticas económicas 0 organizaciones empresariales, sirve para distinguir aquellas iniciativas que aseguren el desarrollo de los objetivos sociales, más allá de en los productos o bienes y servicios ofrecidos, también en los modos en los que estos productos se ofrecen y la cultura económica que llevan asociada. La identificación de la noción de innovación social como una cuestión vinculada con la toma de decisiones democrática contando con la existencia de distintos tipos de actores implicados subraya la innovación social como un atributo vinculado con los procesos a parte de con los resultados o productos ofrecidos.

Esto nos pone delante de la cuestión, no del todo aceptada o reconocida por toda la narrativa sobre innovación social, de que las iniciativas empresariales que producen un beneficio social y a la vez fomentan una cultura económica cuidadosa con el proceso de desarrollo de la actividad económica, -conscientemente basando ese proceso en valores democráticos-, son iniciativas que tienen una historia que trasciende el uso relativamente reciente de la noción de innovación social. Sin duda, como se ha dicho anteriormente, hay un vínculo histórico evidente entre la tradición mutualista y cooperativa iniciada en el siglo XIX y la innovación social entendida como actividad económica con valor social.

Por otro lado la restricción a la apropiación privada de beneficios que plantea la aproximación a la actividad empresarial de las iniciativas de economía social y solidaria pone de relieve una dimensión no capitalista, o anti-capitalista también podríamos decir, de las iniciativas que se caracterizan de manera más rigurosa por los criterios expuestos. Esta cuestión es sensible y en muchos sentidos velada dentro las retóricas referentes a la innovación social y por tanto también dentro del discurso que desarrollan las Administraciones públicas respecto al fomento de la economía social y solidaria.

En definitiva lo que se ha sostenido a lo largo del artículo es que el fomento de la innovación social en las políticas públicas puede ser una oportunidad para el desarrollo de la ESS, pero también se considera importante resaltar que el desarrollo de estas ha sido y está siendo en muchos sentidos independiente de la popularización de las narrativas discursivas vinculadas con la responsabilidad social 


\section{DE LA INNOVACIÓN SOCIAL A LA ECONOMÍA SOLIDARIA. CLAVES PRÁCTICAS PARA EL DESARROLLO DE POLÍTICAS PÚBLICAS}

corporativa por ejemplo. Mucho antes de la popularización de la idea de innovación social, las iniciativas de la ESS, en Europa y en América Latina especialmente vienen realizando pasos para su reconocimiento por parte de las Administraciones. Defourny y Nyssens (2013) nos recuerdan que durante la segunda mitad de la década de los noventa 11 países europeos introdujeron en sus regulaciones nuevas formas legales referentes a la economía cooperativa, social y solidaria. De esta historia reciente y del papel de las entidades del tercer sector en el desarrollo de políticas públicas se derivan debates no abordados directamente en este artículo como el hecho de que el desarrollo de marcos legales tienda a condicionar según los intereses de las Administraciones los objetivos y las prácticas de las empresas sociales. Esta cuestión ha marcado una suspicacia hacia la progresiva pérdida de las características intrínsecas de las empresas sociales como consecuencia de su trato continuado con las Administraciones.

El modelo dominante de reconocimiento público de las empresas de inserción social, por ejemplo, por el momento tiende a reducir su papel en tanto que empresas sociales a un tipo de beneficios que son los propios de su papel funcional para el mercado de trabajo y el apaciguamiento de la conflictividad social. Uno de los retos principales con los que se encuentran las empresas de inserción laboral es encontrar un tipo de producción que se ajuste a las capacidades de los grupos desfavorecidos a los que dan trabajo mientras al mismo tiempo hacen posible el aprendizaje emancipador de esos trabajadores mediante los procesos de producción. Este reto en muchos casos se afronta mediante la estrategia de desarrollar nichos de mercado que no tienen interés por parte de empresas pertenecientes al sector privado tradicional. Pero en el momento en que esos mercados se convierten en más estables y entran en ellos empresas que se rigen por criterios tradicionales, las empresas sociales se pueden ver empujadas a competir según los estándares de las empresas orientadas al beneficio privado.

Esta cuestión, -señalada por la literatura especializada como el problema del isomorfismo institucional-, también se vincula indirectamente por asociación de ideas al tema de la cooptación de miembros de los movimientos sociales por parte de las Administraciones públicas. En esta dirección actualmente una línea de análisis muy pertinente es la que investiga los efectos no buscados derivados del contacto entre entidades socialmente transformadoras u organizaciones ciudadanas y Administraciones públicas.

A la luz del contexto de crisis sistémica actual, y teniendo en cuenta el énfasis por los enfoques participados y los procesos de toma de decisiones que se populariza con las narrativas de innovación social, se pone de relieve la importancia de tener en cuenta las experiencias pasadas. En el caso de las empresas de inserción la importancia de tener en cuenta los objetivos iniciales de las organizaciones que trascienden la sola incorporación en el mercado laboral es uno de los retos actuales. El hecho de que el consumo pueda llegar a ser cada vez más crítico y socialmente responsable, sitúa la cuestión de los procesos de producción en la sociedad del conocimiento en el reto estratégico de tener que rendir cuentas. Esto también atañe al sector social y solidario. 
No debemos subestimar las ventanas de oportunidad que se abren con las crisis sistémicas que estamos viendo desde 2008 y que relacionan finanzas, representatividad política, sociedad, mercado y cultura. Si una nueva consciencia es propia de nuestros tiempos es la consciencia de la interdependencia. La discusión sobre la innovación social, o sobre la posibilidad de un capitalismo socialmente responsable si se quiere, no puede eludir indefinidamente la cuestión de las finanzas éticas por ejemplo. La actuación en la esfera económica ya deja de estar desvinculada de lo que pasa en la esfera política o la esfera cultural. Una cuestión en la que coinciden Miro y Fernández (2013) cuando se les pregunta por innovación social y vinculan la pregunta a la cada vez más evidente cuestión de las muestras de agotamiento del régimen que se pone de relieve en un momento de crisis multidimensional. Que haya evidencias del desmoronamiento del sistema no quiere decir que sus efectos perversos se estén mitigando ni mucho menos. El capitalismo se tambalea como fue entendido durante el siglo veinte, en tanto que sistema de innovación económica sin límites ni implicación ética, desvinculado de la cooperación más allá del paternalismo del Estado del bienestar protector, y escudado en el mito de la competencia perfecta como clave de orden social.

La conciencia de la interdependencia entre áreas de innovación que lleva consigo la popularización en las políticas públicas del concepto de innovación social puede facilitar la identificación de la economía social y solidaria como un conjunto de prácticas especialmente útiles para las Administraciones públicas. Dicho de otra forma, que la innovación social sea invocada por todo tipo de entidades públicas y privadas, podría ser una ventana de oportunidad para articular políticas públicas en favor de una economía social y solidaria comprometida con la gobernanza democrática. Este hecho, en tanto que proceso de institucionalización normalizado y paulatino, puede pasar relativamente al margen de la sospecha que la idea de innovación social viene a ser un recambio lampedusiano del capitalismo tardoavanzado, senil y decadente de las sociedades occidentales de principios del tercer milenio.

\section{8.- Bibliografía}

ANTUÑANO, I. \& GONZÁLEZ, A. (2012): "Reset Economy y Economía Social", CIRIEC-España, Revista de Economía Pública, Social y Cooperativa, 76, 51-73.

ARRIETA, F.J. (2014): "Concreción de las entidades de la Economía Social", REVESCO, Revista de Estudios Cooperativos, 116, 33-56.

BAUHARDT, C. (2014): "Solutions to the Crisis? The Green New Deal, Degrowth, and the Solidarity Economy: Alternatives to the Capitalist Growth Economy from an Ecofeminist Economics Perspective", Ecological Economics, 102, 60-68. 
BERNETE, J. (2013): "Clásulas sociales en la contratación pública: nuevos instrumentos para el fomento del empleo a nivel local", Cuadernos de Trabajo Social, 26(1), 85-94.

BLANCHAR, C. (2016): "Colau no contratará empresas que desvíen fondos a paraísos fiscales", El País, 20/05/2016, http://goo.gl/Bth6Vw

BOULIANNE, M., FRAISSE, L. \& ORTIZ, H. (2003): "The Solidarity Economy and Globalization", La Revue du MAUSS, 47-54.

CHAVES, R. (1997): "La Economía Social como enfoque metodológico, como objeto de estudio y como disciplina científica", CIRIEC-España, Revista de Economía Pública, Social y Cooperativa, 33, 115-140.

CHAVES, R., MONZÓN, J.L., PÉREZ, J.M. \& RADRIGÁN, M. (2013): "La Economía Social en clave internacional. Cuantificación, reconocimiento institucional y visibilidad social en Europa, Iberoamérica y Norte de África", REVESCO, Revista de Estudios Cooperativos, 112, 122-50.

CONILL, J. (2014): "Cultura econòmica alternativa. Canviar la mirada per observar el canvi", Àmbits de Política i Societat, Revista del Col.legi de Politòlegs i Sociòlegs de Catalunya, 1-7.

COQUE, J., LÓPEZ, N. \& LOREDO, E. (2012): "Recuperación de empresas por sus trabajadores en contextos de crisis: ¿qué podemos aprender de experiencias pasadas?", CIRIEC-España, Revista de Economía Pública, Social y Cooperativa, 76, 97-126.

CRESPO, B. \& SABIN, F. (2014): "Los mercados sociales. La Economía Solidaria en acción transformadora", Documentación Social, 174, 95-116.

CORAGGIO, J.L. (2013): "La presencia de la Economía Social y Solidaria (ESS) y su institucionalización en América Latina", May, 21.

DACHEUX, E. \& GOUJON, D. (2011): "The Solidarity Economy: An Alternative Development Strategy?" International Social Science Journal, 62, 205-215.

DEFOURNY, J. \& NYSSENS, M. (2013): "Social Innovation, Social Economy and Social Enterprise: What Can the European Debate Tell Us?". In: The international handbook on Social Innovation. Collective action, Social Learning and Transdiciplinary Research, Moulaert, F. (ed.); MacCallum, D., Mehmood, A. \& Hamdouch, A. Cheltenham: Edward Elgar Publishing, 40-52.

DÍAZ, M. \& MARCUELLO, C. (2010): "Impacto económico de las cooperativas. la generación de empleo en las sociedades cooperativas y su relación con el PIB", CIRIEC-España, Revista de Economía Pública, Social y Cooperativa, 67, 23-44.

DINI, P. (2012): "Community Currencies and the Quantification of Social Value in the Digital Economy", The London School of Economics and Political Science, Retrieved http://eprints.Ise.ac.uk/47349/.

DINI, P. \& KIOPKIOLOIS, A. (2014): "Community Currencies as Laboratories of Institutional Learning: Emergence of Governance through the Mediation of Social Value", LSE Research Online, Retrieved http://eprints.Ise.ac.uk/59307/. 
DUBOIS, J-L. \& LASIDA, E. (2010): "A New Style of Development to Deal with the Current Crisis: Solidarity-Based Economy, Collective Capability and Sustainable Human Development", Revue de philosophie économique, 11:35.

EIZAGUIRRE, S. (2012): Innovació social i governança urbana. Entitats socialment creatives a Barcelona i Bilbao, Tesi doctoral, Departament de Teoria Sociològica, Filosofia del Dret i Metodologia de les Ciències Socials, Universitat de Barcelona.

EIZAGUIRRE, S., PRADEL, M., TERRONES, A., MARTÍNEZ-CELORRIO, X. \& GARCÍA, M. (2012): "Multilevel Governance and Social Cohesion: Bringing Back Conflict in Citizenship Practices", Urban Studies, 49(9), 1999-2016.

ESTIVILL, J. (2014): "L'exercici Innovant de La Solidaritat", Àmbits de Política i Societat, Revista del Col.legi de Politòlegs i Sociòlegs de Catalunya, 1-5.

FERNÁNDEZ, A. \& MIRO, I. (2016): L'economia social i solidària a Barcelona, La Ciutat Invisible, SCCL, Comissionat d'Economia Cooperativa, Social i Solidària - Ajuntament de Barcelona.

FRAISSE, L. (2013): "The Social and Solidarity-Based Economy as a New Field of Public Action: A Policy and Method for Promoting Social Innovation". In: The international handbook on Social Innovation. Collective action, Social Learning and Transdiciplinary Research, edited by Abid Mehmood and A. Hamdouch Moulaert, F., MacCallum, D. Cheltenham: Edward Elgar Publishing, 346-360.

GARCÍA JANÉ, J. (2012): "El Olmo de La Economia Solidaria", Mientrastanto, 105.

GARCÍA JANÉ, J. (2014): "La Caixa D'eines de L'economia Social I Solidària: Reparar I Construir." In: Guia d'economia social i solidària per a l'administració local, Barcelona: Diputació de Barcelona, 21-46.

GARCÍA MULLER, A. (2012): "Cómo determinar qué entidades forman parte de la economía social y solidaria", UNISANGIL Empresarial, 5(1), 39-46.

GEROMETTA H., HAUSSERMANN, G. \& LONGO, J. (2005): "Social Innovation and Civil Society in Urban Governance: Strategies for an Inclusive City”, Urban Studies, 42(11), 2007-2021.

GURRUTXAGA, A. (2011): "Condiciones y condicionamientos de la Innovación Social", Arbor, 187(752), 1045-1064.

GURRUTXAGA A. \& UNCUETA, A. (2006): "Hacia una historia comparada de la innovación. Cambio, complejidad y globalización", Historia Contemporánea, 32, 129-160.

HERRAN, P.J. (2013): "La economía popular y solidaria. Una práctica más que un concepto", Retos III , 5, 35-42.

INGLADA, E. \& SASTRE, J.M. (2014): "Reflexiones sobre la globalización, pobreza y desarrollo: incidencia en las organizaciones de economía social", REVESCO, Revista de Estudios Cooperativos, 116, 160-179. 
JIMÉNEZ, J. \& MORALES A.C. (2011): "Social Economy and the Fourth Sector, Base and Protagonist of Social Innovation", CIRIEC-España, Revista de Economía Pública, Social y Cooperativa, 73, 33-60.

LAVILLE, J-L. (2010): "The Solidarity Economy: An International Movement", RCCS Annual Review.

LEVESQUE, B. (2013). "Social Innovation in Governance and Public Management Systems: Towards a New Paradigm?". In: The international handbook on Social Innovation. Collective action, Social Learning and Transdiciplinary Research, edited by Frank Molulaert, Diana MacCallum, Abid Mehmood, and Abdelillah Hamdouch, Edward Elgar Publishing, 25-39.

MARTINELLI, F. (2013): "Learning from Case Studies of Social Innovation in the Field of Social Services: Creatively Balancing Top-down Universalism with Bottom-up Democracy". In: Social innovation: Collective action, Social learning and Transdisciplinary research, edited by F. Moulaert; Moulaert, F., MacCallum, D., Mehmood, A., \& Hamdouch, A. Cheltenham: Edward Elgar Publishing, 346-359.

MIRÓ, I. \& FERNÁNDEZ, D. (2013): "Els tres esgotaments del règim (o la necessitat d'institucions del comú)", Àmbits de Política i Societat.

MONZÓN, J.L. (2006): "Economía social y conceptos afines: fronteras borrosas y ambigüedades conceptuales del tercer sector", CIRIEC-España, Revista de Economía Pública, Social y Cooperativa, $56,9-24$.

MOULAERT, F. \& NUSSBAUMER, J. (2005): "The Social Region. Beyond the Learning Economy", European Urban and Regional Studies, 12(1), 45-64.

MOULAERT, F. (2009): "Social Innovation and Territorial Development", Social Innovation and Territorial Development, 11-23.

MOULAERT, F., MACCALLUM, D., MEHMOOD, A. \& HAMDOUCH, A. (2013): The International Handbook on Social Innovation. Collective Action, Social Learning and Transdisciplinary Research, Cheltenham: Edward Elgar Publishing.

NOVY, A., COIMBRA DE SOUZA, D. \& MOULAERT, F. (2012): "Social Cohesion: A Conceptual and Political Elucidation", Urban Studies, 49(9), 1873-1889.

NUNES, C. \& FERREIRA, G. (2007): "Public Policies for Solidarity-Based Economy in Brazil. Labor, Inclusion and Social Capital", Revue Tiers Monde, 48, 379-399.

OLIVERES, A. (2006): Un Altre Món, Barcelona: Angle Editorial.

PANIAGUA, M. (2013): "Las empresas de inserción sociolaboral y las cláusulas sociales en la contratación pública: dos instrumentos necesarios para la innovación social hacia el desarrollo", REVESCO, Revista de Estudios Cooperativos, 112, 176-212.

PARES, M. (2015): Repensant la participació de la ciutadania al món local, Col.lecció Barcelona: Diputació de Barcelona.

PÉREZ, P.E. (2013): "Investigación documental ética y responsabilidad social (RS) en las empresas de Economía Solidaria", Revista Económicas CUC, 34(2), 51-66. 
PLACE, C. \& BINDEWALD, L. (2015): "Validating and Improving the Impact of Complementary Currency Systems through Impact Assessment Frameworks", International Journal of Community Currency Research, 19, 152-164.

PRADEL, M., EIZAGUIRRE, S. \& GARCÍA, M. (2013): "Theorising Multi-Level Governance in Social Innovation Dynamics". In: Social innovation: Collective action, Social learning and Transdisciplinary research, edited by F. Moulaert; MacCallum, D., Mehmood, A. \& Hamdouch, A. Cheltenham: Edward Elgar Publishing, 155-168.

PRIMAVERA, H. (2010): "Social Currencies and Solidarity Economy: an Enduring Bond of Common Good", WorkingUSA, 13, 41-59.

RUIZ, M. \& RETOLAZA, J.L. (2005): "La auditoría social como instrumento de posicionamiento de la Economía Solidaria", CIRIEC-España, Revista de Economía Pública, Social y Cooperativa, 53, 285-304.

RUIZ, M., RETOLAZA, J.L. \& MUGARRA, A. (2007): "Cláusulas sociales y mercados tutelados: herramientas para la competitividad de las empresas de inserción", CIRIEC-España, Revista de Economía Pública, Social y Cooperativa, 59, 123-151.

SINGER, P. (2009): "Relaciones entre sociedad y Estado en la Economía Solidaria", Iconos, Revista de Ciencias Sociales, 33, 51-65.

SUBIRATS, J. (2014): "Notes sobre canvi d'època i economia social. Noves polítiques de desenvolupament local?". En: J. Garcia Jané (Ed.), Guia d'economia social i solidària per a l'administració local, Barcelona: Diputació de Barcelona, 9-20.

SOCIAS, A. \& HORRACH, P. (2013): "Enfoque de la responsabilidad social y la transparencia en empresas de economía solidaria", CIRIEC-España, Revista de Economía Pública, Social y Cooperativa, 77, 31-57.

VAILLANCOURT, Y. (2011): "El 'mapeo' de la Economía Social y Solidaria: algunos retos", Otra Economía, Retrieved http://www.unisinos.br/revistas/index.php/otraeconomia/article/view/1309/37.

VALOR, C. (2006): "Cláusulas Sociales Análisis de La Afinidad de Objetivos Con El Movimiento Por El Comercio Justo", Boletín económico del ICE, 2882, 39-54.

VIDAL, I. (2008): "Más allá del Estado del Bienestar: Nuevas tendencias en las políticas de bienestar en España: Implicaciones para las organizaciones sin ánimo de lucro", $19^{\circ}$ Encuentro Anual de la Johns Hopkins International Philanthropy Fellows, Universidad de Barcelona.

VV.AA. (2014): Guia d'Economia Social i Solidària per a l'Administració Local, J. Garcia (Ed.), Diputació de Barcelona.

XARXA D'ECONOMIA SOLIDÀRIA (2015): 14 mesures per impulsar l'economia social i solidària a nivell local, http://www.xes.cat/docpdf/xsa1072.pdf. 